\title{
SUSTENTABILIDADE, CERTIFICAÇÃO \\ LEED E USUÁRIO: ESTUDO EM RETROFIT \\ DE EDIFÍCIO CORPORATIVO
}

\section{SUSTAINABILITY, LEED CERTIFICATION AND USER: CORPORATE BUILDING RETROFIT STUDY}

\author{
ISABELA FRANCO SCHREIBER, M.SC. | UNISINOS \\ MATHEUS VANZIN VERONA | UNISINOS \\ FERNANDA PACHECO, M.SC. | UNISINOS \\ DANIEL REIS MEDEIROS, Dr. UUNISINOS \\ MARIA FERNANDA DE OLIVEIRA, Dra. | UNISINOS
}

\begin{abstract}
RESUMO
O retrofit amplia o desempenho e a vida útil da edificação, possibilitando aliar questões de sustentabilidade ambiental, social e econômica, com estética e funcionalidade. O presente estudo de caso avaliou diretrizes projetuais, visando aliar soluções sustentáveis e economicamente viáveis ao projeto e execução de um retrofit de edificação comercial, em São Leopoldo, RS, utilizando elementos estéticos atuais e corporativos, almejando a satisfação dos usuários. O estudo iniciou com levantamentos, incluindo visitas na edificação existente e aplicação de um questionário de avaliação pós-ocupação (APO), identificando elementos passíveis de modificação e sem alterações estruturais significativas, para definição das diretrizes projetuais, conforme as exigências da certificação LEED para grandes reformas e interiores comerciais. Apresentam-se os projetos da proposta desenvolvida e o acompanhamento de sua execução. Após, aplicou-se novo APO, para avaliar as soluções de projeto. O comparativo entre os questionários demonstra o aumento dos níveis de satisfação dos usuários, em relação ao conforto e bem-estar e evidencia a importância de uma APO para algumas definições do retrofit da edificação.
\end{abstract}

PALAVRAS CHAVE: Retrofit; Arquitetura Corporativa; Qualidade no trabalho; Avaliação Pós-Ocupação; Satisfação do usuário

\begin{abstract}
Retrofit enhances the performance and expands the lifetime of a building as well as enables the combination of environmental, social and economic sustainability issues with its aesthetical and functional aspects. Therefore, this case study aimed to assess the adopted strategies in a commercial building located in the city of São Leopoldo Rio Grande do Sul, Brazil, by joining sustainable and economically feasible solutions to the project and applying retrofit by using current aesthetical and corporate elements to improve user satisfaction. Initially, data were collected through on-site visits in order to assess the existing building and apply a post-occupation evaluation (POE) questionnaire. These visits were also intended to identify elements associated with the characteristics of the existing building that could be modified. Subsequently, the design guidelines were defined according to the LEED certification for New Construction \& Major Renovation and for Commercial Interiors. This paper presents the designs of the new proposal developed as well as the images of the construction process until its conclusion, when a new POE questionnaire was applied to verify the design solutions. The comparison between the questionnaires demonstrates an increase in user satisfaction levels after the application of retrofit and the importance of POE for building retrofit design definitions.
\end{abstract}

KEY WORDS: Retrofit; Corporate Architecture; Quality in the workplace; Post-occupation evaluation; User satisfaction. 


\section{INTRODUÇÃO}

Oferecer espaços agradáveis nas instituições estimula o comprometimento do funcionário, bem como resulta em aumento na produtividade (FONSECA, 2004). Para desenvolver um projeto arquitetônico corporativo, em que forma e função atendam aos objetivos da empresa de modo eficiente, agradável e que promova o bem-estar, é indispensável conhecer o organograma da empresa, dos elementos e recursos que estão ou não adequados e das necessidades básicas, além de obter informações dos usuários. Faz-se assim, da arquitetura uma ferramenta gerencial (GURGEL, 2014; PIQUETTI, 2012).

Além disso, para aliar questões de sustentabilidade ambiental, social e econômica, com aspectos estéticos, funcionais, qualidade, saúde e segurança do ambiente, em edificações consolidadas que necessitam alterar seu uso, uma abordagem que vem ganhando espaço no Brasil é o Retrofit, pois colabora para uma melhora no desempenho e pode aumentar a vida útil da edificação. (VALE, 2006).

Retrofit é entendido com a requalificação de uma edificação, que muitas vezes pode envolver a troca de usos, com amplas oportunidades de qualificação do seu desempenho energético, sendo um dos aspectos indicados para a promoção da construção sustentável (PNUMA, 2014). Nesse sentido, um retrofit planejado de forma adequada oferece possibilidades de atualização construtiva, tanto em aspectos das tecnologias construtivas, quanto em relação à concepção original do projeto arquitetônico.

Segundo Silva e Pardini (2011), pode-se indicar uma dicotomia nos assuntos relacionados à sustentabilidade na construção civil. Se por um lado a mensuração dos seus benefícios ainda apresenta complexidade, por outro, não há como refutar o reconhecimento e ganhos em termos mercadológicos com fortalecimento da imagem da marca. As autoras também citam que existe uma percepção no país de que as edificações sustentáveis têm um custo inicial maior, mas que ainda falta a percepção de que, uma parcela importante desses custos é resultado de dificuldades relacionadas à mudança de procedimentos e abordagens correntes para se obter resultados de alguma maneira superiores. Agopyan e Jonh (2012) indicam ainda que, além de envolver um conceito a longo prazo, a sustentabilidade requer uma visão sistêmica, para que a sua viabilidade seja definida a partir de indicadores compatíveis com o tempo de vida útil das edificações.

Este estudo de caso foi realizado em uma edificação de dois pavimentos, localizada em São Leopoldo, que abriga a sede administrativa de empresa de suprimentos corporativos, com diferentes aspectos de sustentabilidade em seus valores. Ao longo dos anos, a edificação analisada, passou por diversas intervenções e ampliações, passando de uso misto para uso somente comercial. A troca entre usuários da edificação conduziu a uma divisão equivocada dos departamentos, prejudicando a organização da empresa, comprometendo a qualidade do ambiente de trabalho. Com base nas expectativas da empresa pela busca da sustentabilidade e melhoria dos ambientes, foram realizados: levantamentos in loco, entrevistas com os usuários e leituras específicas. Percebeu-se a necessidade de realizar uma intervenção arquitetônica completa, desde a fachada até o interior.

O desenvolvimento do trabalho foi pautado na busca pela adoção de parâmetros de sustentabilidade, conforme a Certificação LEED para grandes reformas e interiores comerciais, que estabelece metas relacionadas as condições locais e usos da edificação, para definições de projeto, escolha de materiais e acabamentos. Ao final do retrofit os níveis de satisfação dos usuários foram quantificados para analisar o impacto das intervenções, e se atenderam ao propósito de melhorar a qualidade do ambiente de trabalho. Buscou-se, assim, satisfazer o objetivo desse estudo, de avaliar as estratégias utilizadas como diretrizes projetuais, a fim de aliar soluções sustentáveis e economicamente viáveis ao projeto e execução de um retrofit em uma edificação comercial, através de alterações de layout, modificações na fachada e utilização de elementos atuais e corporativos, com o propósito de melhorar o conforto e a satisfação dos usuários.

\section{MÉTODO}

Para atingir os objetivos propostos, o estudo foi realizado em etapas, e para facilitar o acompanhamento das ações correspondentes a cada um destes passos, foi elaborado um diagrama (Figura 1). Para avaliação da viabilidade da execução do retrofit foram utilizadas as metodologias descritas por Barrietos e Qualharini (2004) e Moraes e Quelhas (2012), que indicam um roteiro de procedimentos para auxiliar na tomada de decisões. Tal roteiro foi iniciando pelo pré-diagnóstico, no qual a situação inicial da qualidade e do estado de conservação da edificação é analisada. Nessa etapa foram realizados levantamentos da memória do projeto e da construção, cadastro e registro atualizado das alterações dos ambientes construídos (as built) e entrevistas com os gestores dos funcionários da empresa. Na etapa seguinte foi realizado o diagnóstico através de uma vistoria com registro fotográfico, pesquisa documental, aplicação de questionário, entrevista com o proprietário da empresa, e medições físicas. 
Os instrumentos utilizados foram definidos com base em estudos anteriores de Issa, Poltronieri e Ornstein (2008) e de Ono et al. (2018) conforme o ponto de vista do especialista; leitura dos projetos e as built; checklists e walkthroughs e, observações; o ponto de vista do usuário: entrevistas; passeios guiados e questionários.

A etapa seguinte consiste na definição do diagnóstico para determinar as diretrizes projetuais e critérios de reaproveitamento de matérias e sistemas, e em seguida o desenvolvimento do projeto arquitetônico definitivo, e projetos complementares específicos, para então iniciar a execução das obras. As obras de retrofit foram realizadas durante 08 meses, entre maio de 2015 e janeiro de 2016, com todos os usuários trabalhando no prédio.

Após o término da obra foi aplicado um novo questionário de Avaliação Pós-Ocupação (APO), no mês de maio de 2016 aos colaboradores, para ser comparado com os resultados do primeiro questionário, e dessa forma, possibilitar a verificação dos índices de satisfação dos usuários antes e depois do retrofit. Aproximadamente 30\% dos funcionários que responderam ao segundo questionário não trabalhavam no prédio há mais de 12 meses.

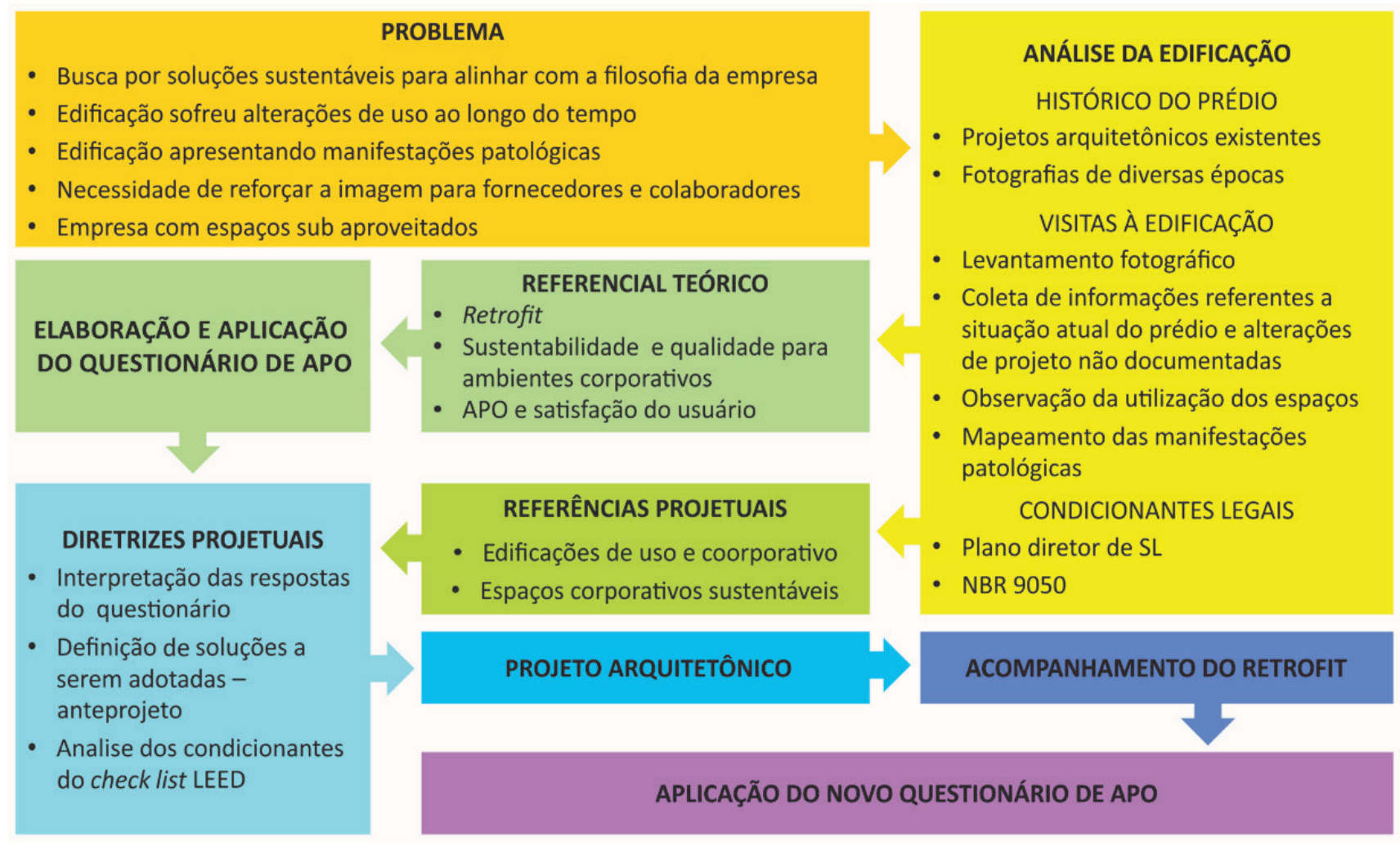

Figura 1 - Diagrama de Pesquisa

Fonte: 0 s autores

\section{DIAGNÓSTICO E RESULTADOS}

\subsection{Levantamentos Preliminares}

Os levantamentos realizados "in loco", ocorreram durante os meses de abril e maio de 2015, em diferentes horários e dias da semana, para auxiliar na compreensão do programa de necessidades, sugerido pelo proprietário. Conforme indicação de Ono et al (2018), foram observados o uso e a ocupação dos ambientes, bem como foi realizada a conferência de medidas para confecção do "as built" e o levantamento dos danos patológicos.

O layout interno estava distribuído em dois pavimentos, sendo que o acesso principal era realizado pela escadaria da fachada norte, e o acesso secundário, para funcionários, pela fachada oeste. Conforme informações do proprietário do imóvel, quando houve a unificação dos prédios, em 2008, o prédio original e a edificação vizinha apresentavam diferenças de níveis e a solução adotada foi construir uma escada que ligasse as duas partes, porém somente pelo pavimento térreo.

O pavimento térreo era composto pela recepção, área para o departamento comercial e departamento de compras, área de convivência e sanitários, conforme Figura 2. 


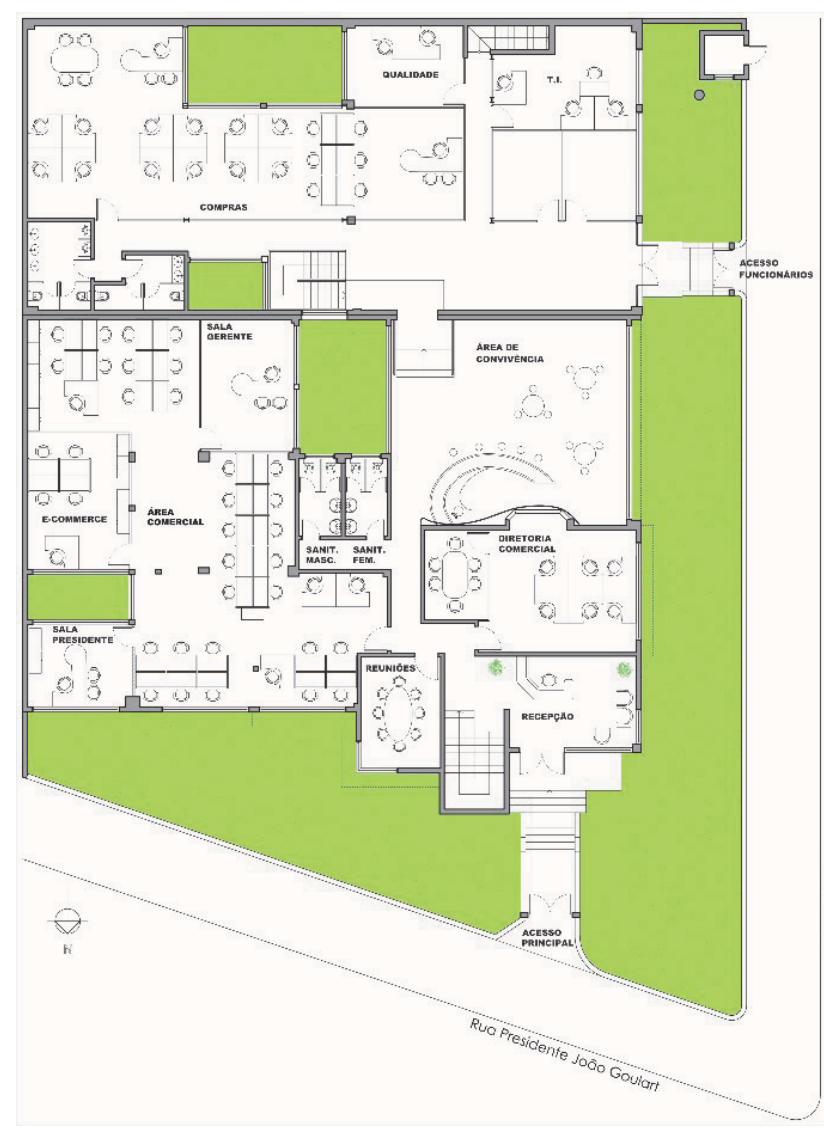

Figura 2 - Planta baixa do térreo

Já no pavimento superior, acessado através da recepção, estavam localizadas as salas para os departamentos financeiro e pessoal, além de uma churrasqueira e área de lazer que havia sido concebida para a antiga residência (Figura 3). O segundo pavimento da edificação incorpora$\mathrm{da}$, estava totalmente inutilizado, mesmo possuindo uma ampla sala de call center mobiliada, arquivo, sala de brindes e sanitários (Figura 3).

Através das Figuras 4 a 8 é possível observar como eram os ambientes anteriormente ao retrofit.

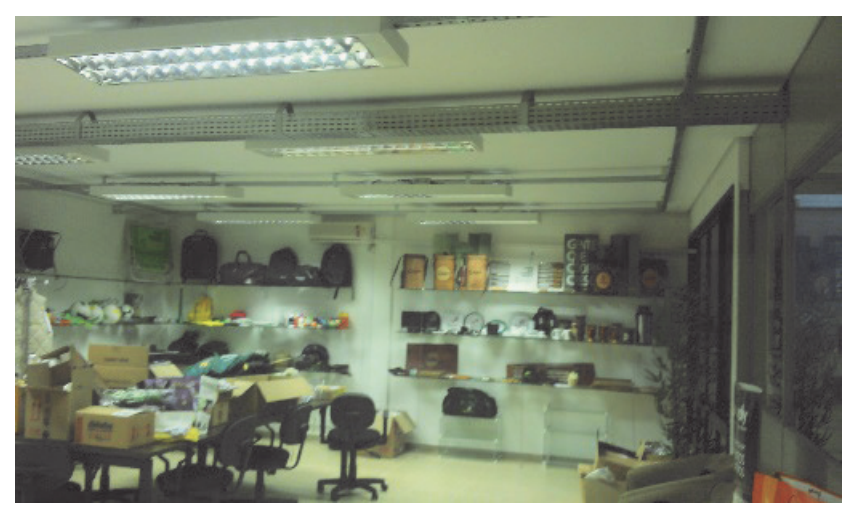

Figura 4 - Sala de Brindes Fonte: 0 s autores

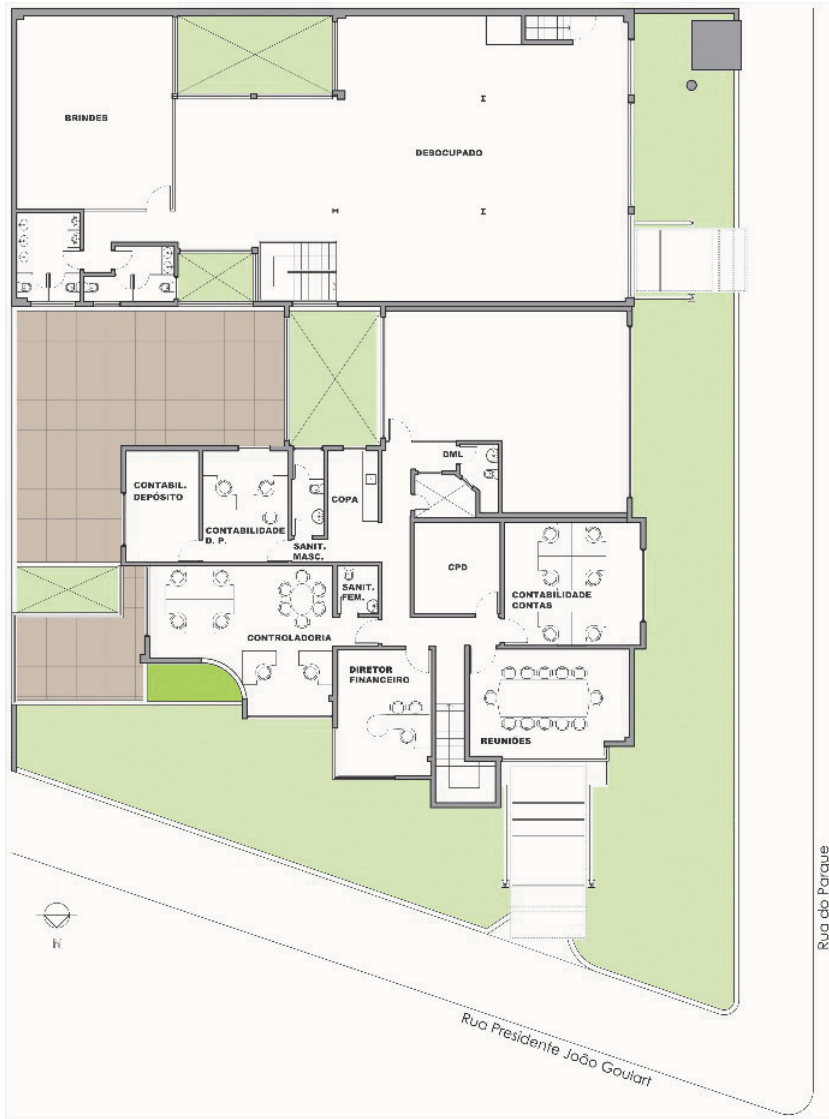

Figura 3 - Planta baixa do segundo pavimento Fonte: 0 s autores

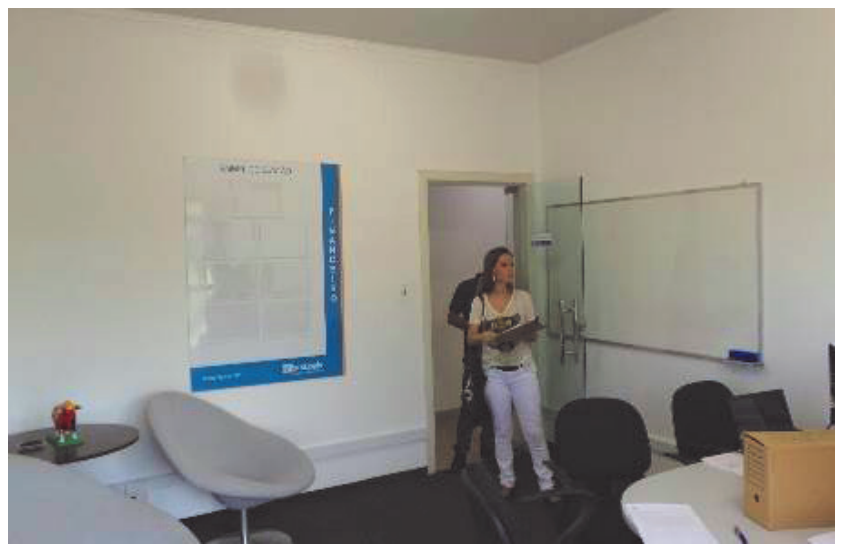

Figura 5 - Sala de Reuniões Estratégicas Fonte: 0 s autores

Durante as visitas ao local, pode-se notar que o deck de convívio (Figura 7) que ligava os dois prédios pelo térreo e a copa (Figura 8) do segundo pavimento permaneciam sem ocupação, diferentemente das salas de reuniões e as salas dos departamentos (Figuras 5 e 6) que estavam sempre ocupadas. Como cada setor ocupava o espaço correspondente aos antigos cômodos do prédio, as salas ficaram com uma distribuição heterogênea de usuários, por vezes muito vazias, como a sala de 
brindes (Figura 4) ou com muita ocupação, como na contabilidade (Figura 6). De qualquer modo, foi verificado que não havia integração entre os espaços, situação que se agravava quando um setor maior precisava ser divido em diversos ambientes, como a controladoria, a contabilidade e o departamento pessoal, todas pertencentes ao setor financeiro.

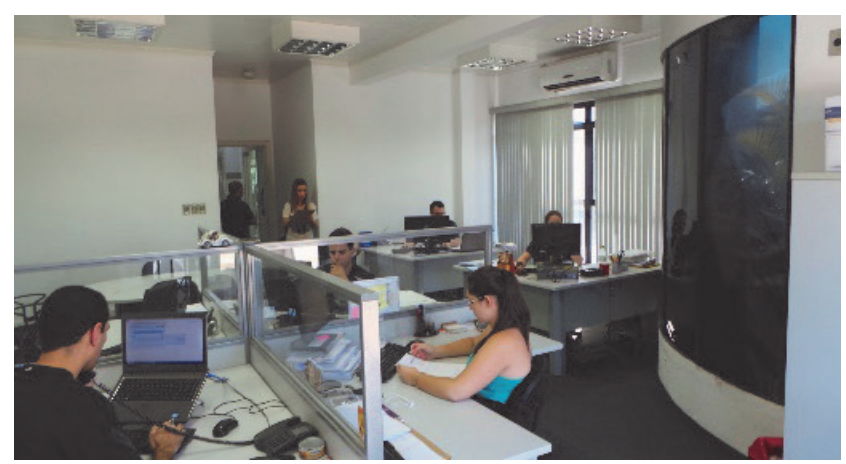

Figura 6 - Sala Contabilidade Fonte: 0 s autores

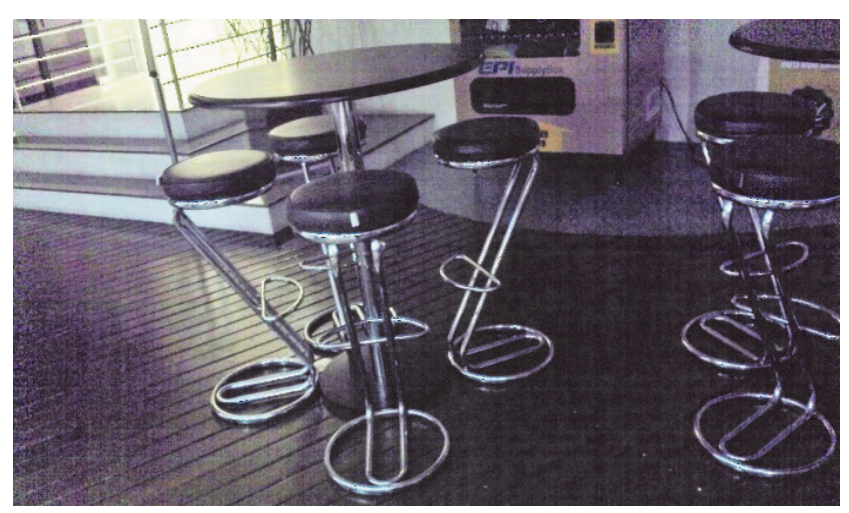

Figura 7 - Deck de convívio

Fonte: 0 s autores
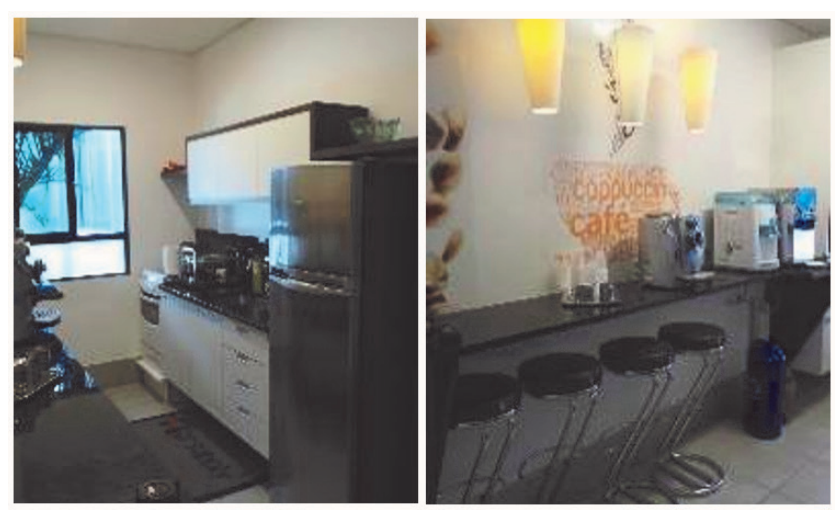

Figura 8 - Copa e área de convívio

Fonte: 0 s autores

Também, foi possível observar que o prédio apresentava inúmeras manifestações patológicas, principalmente devido às infiltrações pelo telhado, ralos, rejuntes e descolamentos de revestimento cerâmico nos terraços, ausência de capa nos muros na divisa, pingadeiras instaladas com caimento invertido, também em decorrência de instalações mal executadas (Figura 9). Também foram observados forros de PVC soltos no espaço de depósito, única área com este tipo de acabamento, quadros elétricos inadequados e fora de norma bem como eletrocaIhas, perfilados e eletrodutos com excesso de cabos. Destaca-se também: torneiras e caixa acoplada dos vasos sanitários com vazamento ou em mau funcionamento e principalmente uma má distribuição do layout, tendo sanitários desativados, áreas desocupadas e/ou subaproveitadas, que não estavam sendo utilizadas para o fim que foram projetadas.
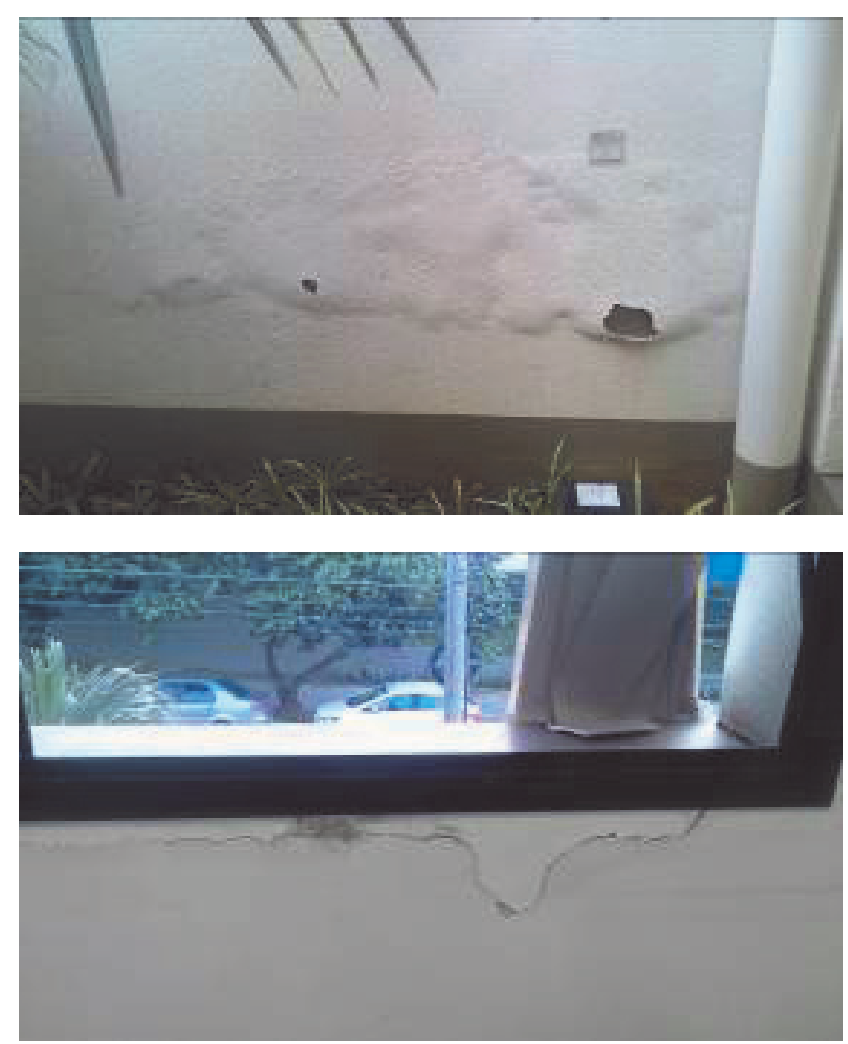

Figura 9 - Danos causados por Infiltrações diversas

Fonte: 0 s autores

Externamente, a edificação se apresentava de forma única, não sendo possível identificar que anteriormente as unidades distintas. A fachada também exibia algumas manifestações patológicas, como descolamento das pastilhas cerâmicas que revestiam as platibandas, e infiltrações nas paredes de divisa (Figura 10), em decorrência da falta de manutenção preventiva. Havia também poucas janelas para a rua e terraços subutilizados que tinham o acesso restrito a apenas dois ambientes. 


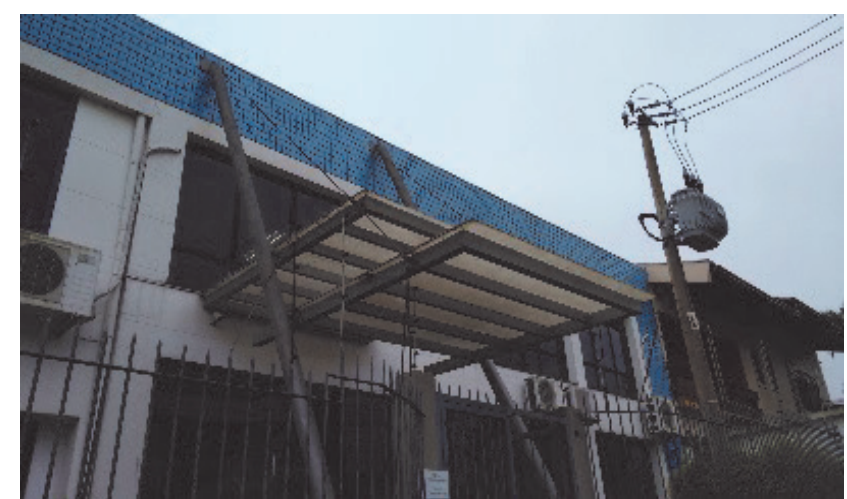

Figura 10 - Manifestações patológicas Fonte: 0 s autores

\subsection{Aplicação e análise do primeiro questionário}

Como o propósito deste retrofit abrangia também as necessidades dos usuários, estes foram convidados a responder um questionário online, de forma anônima, para que houvesse uma amostragem representativa do todo. A aplicação do primeiro questionário, foi realizada entre os dias 30 de junho e 03 de julho de 2015, e 41 pessoas responderam ao questionário, permitindo trabalhar com as informações de $67 \%$ dos 61 ocupantes do prédio.

As variáveis subjetivas, foram avaliadas com uma escala de valores, limitadas entre "muito insatisfeito" e "muito satisfeito", conforme sugerem Rheingantz et al. (2009). Questionouse a satisfação do usuário quanto a aspectos que envolvem desde o número de sanitários disponíveis até materiais e acabamentos. Opcionalmente, foi disponibilizado um espaço para preenchimento manual, onde os funcionários poderiam explicar os motivos de algumas das suas respostas.

O resultado indicou que os usuários consideravam satisfatórios os itens de iluminação natural, acessibilidade, organização interna e disposição do mobiliário, espaço para mesa de trabalho, espaços de conveniência, materiais de acabamento como pisos, divisórias e cores dos ambientes e interferência de ruídos externos. Por outro lado, os resultados insatisfatórios se deram em questão à quantidade dos sanitários e interferência de ruídos internos. Para questões de ventilação, climatização e qualidade do ar interno, houve um equilíbrio nas respostas. As demais perguntas diziam respeito à preferência quanto a ventilação, a iluminação e os níveis de interação entre usuários e foram elaboradas para resposta única.

Através das informações analisadas, com base nas experiências dos funcionários da empresa, foram tabulados os resultados, conforme orientam Ono et al (2018), e diagnosticados como aspectos negativos: a pouca quantidade de sanitários, os ruídos internos que atrapalham a concentração, o acendimento permanente das luzes e a falta de janelas para a rua.
Como aspectos positivos foram identificados: os móveis e dimensão das mesas, assim como acabamentos de pisos, divisórias e cores dos ambientes. Foi indicado que os ruídos externos atrapalham pouco na concentração, $e$ a acessibilidade foi considerada como um ponto positivo, mesmo que o prédio não possua rampas, e os prédios não sejam unificados na parte superior. Quanto às áreas de convivência, a maioria dos usuários se mostrou satisfeita, mas tanto nas visitas quanto nas respostas se observou que estas áreas são pouco utilizadas.

Os itens de iluminação, ventilação, climatização e qualidade do ar tiveram respostas com a expressão indiferente, assim como a integração com os colegas, pois enquanto uns preferem trabalhar em equipe outros preferem trabalhar sozinhos.

\subsection{DEFINIÇÃO DAS DIRETRIZES PROJETUAIS}

Com base nos resultados das etapas anteriores, análise da edificação, e como resultado da primeira APO, foram definidas as diretrizes projetuais de modo a atender as necessidades dos usuários, aos condicionantes legais e aos critérios da certificação LEED BD+C para grandes reformas e LEED $\mathrm{ID}+\mathrm{C}$ para interiores comercias, a fim de qualificar o ambiente de forma sustentável, após a realização do retrofit.

Foram utilizadas como referências para as definições deste projeto quatro critérios da certificação LEED: Eficiência hídrica, Energia e atmosfera, Matérias e recursos e Qualidade do ambiente interno.

\section{a) Uso Racional da Água}

Esta categoria visa promover a eficiência hídrica, reduzindo o consumo de água potável e buscando soluções para o tratamento e reuso dos recursos (United States Green Building Council - USGBC). Para o projeto em questão foram definidas as ações da Tabela 1.

\begin{tabular}{|c|c|}
\hline \multirow{4}{*}{ 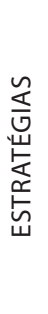 } & $\begin{array}{l}\text { Substituir os mecanismos das caixas acopladas por sistemas } \\
\text { de duplo acionamento, e os mictórios por modelos mais } \\
\text { econômicos. }\end{array}$ \\
\hline & $\begin{array}{l}\text { Substituir as torneiras existentes por modelos de } 1 / 2 \text { volta, } \\
\text { com arejadores e redutores de pressão }\end{array}$ \\
\hline & $\begin{array}{l}\text { Reaproveitar a água de condensação dos aparelhos de ar } \\
\text { condicionado como parte da irrigação dos jardins }\end{array}$ \\
\hline & Identificar vazamentos em toda a rede hidráulica \\
\hline
\end{tabular}

Tabela 1 - Eficiência Hídrica - Estratégias

Fonte: 0 s autores

A Tabela 2 utilizou o número e o proporcional de funcionários homens e mulheres para comparar o consumo entre as bacias sanitárias, mictórios, e torneiras de banheiros existentes e as novas peças instaladas, comprovando que a 
economia de água pode chegar a 48,82\% frente a base de cálculo da certificação LEED, denominada baseline. (USGBC).

b) Energia e Atmosfera

Na categoria Energia e Atmosfera os créditos buscam promover a eficiência energética da edificação, visando a redução do consumo energético através de estratégias de projeto e uso de fontes renováveis. As diretrizes adotadas para atender a estes propósitos estão descritas na Tabela 3 (USGBC).

c) Materiais e Recursos

Para atender as exigências de materiais e recursos, que abrangem a produção e uso de materiais com reduzido impacto ambiental, bem como a destinação correta dos resíduos gerados pelas construções, durante a obra foi estabelecida uma gestão de resíduos da construção, prevendo um descarte correto das lâmpadas existentes, e dos entulhos, separando-os em caçambas de acordo com o tipo do material, e certificando-se de que o descarte foi feito em local licenciado ambientalmente. Além destas, foram tomadas decisões que envolvem não só a obra, como toda política da empresa, como a instalação de pontos de coleta seletiva de materiais reciclados, e utilização de produtos a seco, qualificados tanto para a limpeza pós obra, como para o uso diário. (USGBC).

\begin{tabular}{|l|l|l|l|}
\hline Baseline & \multicolumn{2}{|l|}{1 galão $=3,785$ I } \\
\hline Bacia sanitária & 1,6 galão/descarga & 6,056 I & \\
\hline Mictório & 1 galão/ descarga & 3,785 I & \\
\hline Torneira & 2,2 galão/min & 1,67 I & \\
\hline
\end{tabular}

\begin{tabular}{|c|c|c|c|c|c|}
\hline \multicolumn{2}{|l|}{61 funcionários } & \multirow{2}{*}{$\begin{array}{l}\text { Vezes de uso } \\
1 \mathrm{x} \\
1 \mathrm{x} \\
2 \mathrm{x}\end{array}$} & \multirow{2}{*}{$\begin{array}{l}\text { Usos/Dia } \\
25 \\
18 \\
36\end{array}$} & \multirow{2}{*}{$\begin{array}{l}\text { Litros Base } \\
6,05 \\
6,05 \\
6,05\end{array}$} & \multirow{2}{*}{$\begin{array}{l}\text { Consumo Total } \\
\text { (Litros/Dia) }\end{array}$} \\
\hline Bacia Sanitária & $\begin{array}{l}25 \text { - homens } \\
18 \text { - mulheres } \\
18 \text { - mulheres }\end{array}$ & & & & \\
\hline Mictório & $\begin{array}{l}25 \text { - homens } \\
0 \text { - mulheres }\end{array}$ & $2 x$ & 25 & 3,78 & 94,5 \\
\hline Torneira & $\begin{array}{l}25 \text { - homens } \\
36-\text { mulheres }\end{array}$ & $\begin{array}{l}3 x \\
3 x\end{array}$ & $\begin{array}{l}75 \\
108\end{array}$ & $\begin{array}{l}1,67 \\
1,67\end{array}$ & $\begin{array}{l}125,25 \\
180,36\end{array}$ \\
\hline & & \multicolumn{2}{|c|}{ Total: 287 usos/dia } & \multicolumn{2}{|c|}{ Total: 878,06 litros/dia } \\
\hline & & \multicolumn{4}{|c|}{264 dias úteis / ano } \\
\hline & & \multicolumn{4}{|c|}{ Consumo total anual: $231.807,80$ litros/ano } \\
\hline
\end{tabular}

\begin{tabular}{|l|l|l|}
\hline Projeto & Válvula descarga dual & 3 e 6 litros/ descarga \\
\hline Bacia sanitária & Pressmatic - Docol & 0,7 litros/descarga \\
\hline Mictório & Pressmatic - Docol & 1,8 litros/minuto \\
\hline Torneira &
\end{tabular}

\begin{tabular}{|c|c|c|c|c|c|}
\hline \multicolumn{2}{|l|}{61 funcionários } & \multirow{2}{*}{$\begin{array}{l}\text { Vezes de uso } \\
1 \mathrm{x} \\
1 \mathrm{x} \\
2 \mathrm{x}\end{array}$} & \multirow{2}{*}{$\begin{array}{l}\text { Usos/Dia } \\
25 \\
18 \\
36\end{array}$} & \multirow{2}{*}{$\begin{array}{l}\text { Litros Base } \\
6 \\
6 \\
6\end{array}$} & \multirow{2}{*}{$\begin{array}{l}\text { Consumo Total } \\
\text { (Litros/Dia) }\end{array}$} \\
\hline Bacia Sanitária & $\begin{array}{l}25 \text { - homens } \\
18 \text { - mulheres } \\
18 \text { - mulheres }\end{array}$ & & & & \\
\hline Mictório & $\begin{array}{l}25 \text { - homens } \\
0 \text { - mulheres }\end{array}$ & $2 x$ & 25 & 07 & 17,5 \\
\hline Torneira & $\begin{array}{l}25 \text { - homens } \\
36-\text { mulheres }\end{array}$ & $\begin{array}{l}3 x \\
3 x\end{array}$ & $\begin{array}{l}75 \\
108\end{array}$ & $\begin{array}{l}0,36 \\
0,36\end{array}$ & $\begin{array}{l}27 \\
38,88\end{array}$ \\
\hline & & \multicolumn{2}{|c|}{ Total: 287 usos/dia } & \multicolumn{2}{|c|}{ Total: 449,38 litros/dia } \\
\hline & & \multicolumn{4}{|c|}{264 dias úteis / ano } \\
\hline & & \multicolumn{4}{|c|}{ Consumo total anual: $118.636,32$ litros/ano } \\
\hline
\end{tabular}

Tabela 2 - Comparativo de Consumo de água

Fonte: 0 s autores 


\begin{tabular}{|c|c|c|}
\hline \multirow{8}{*}{ 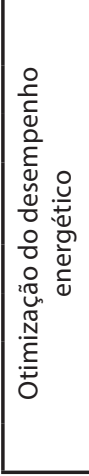 } & Iluminação & Realizar cálculo luminotécnico para quantificar a iluminância conforme o uso dos ambientes e das normas da ABNT. \\
\hline & \multirow{2}{*}{$\begin{array}{l}\text { Controle } \\
\text { de luz }\end{array}$} & Redistribuir os circuitos elétricos de forma independente para controle da iluminação nas áreas de trabalho e circulações. \\
\hline & & Instalar sensores de presença nos sanitários. \\
\hline & \multirow[t]{5}{*}{$\begin{array}{l}\text { Ar } \\
\text { Condicionado }\end{array}$} & $\begin{array}{l}\text { Mapear as máquinas instaladas, incluindo potência e classificação do Selo Procel, para verificar quais poderiam ser } \\
\text { mantidas e para quais ambientes seriam necessários novos equipamentos tipo Split Inverter e Cassete (classe A e B). }\end{array}$ \\
\hline & & Dimensionar o sistema de AC, conforme as áreas, usos e incidência de calor nos ambientes. \\
\hline & & Limpar filtros dos aparelhos de ar condicionado reaproveitados. \\
\hline & & $\begin{array}{l}\text { Utilizar telha tipo sanduiche, tanto na cobertura do novo espaço construído, quanto para substituir a cobertura de } \\
\text { toda a área sem laje e que apresentava infiltrações. }\end{array}$ \\
\hline & & Pintar a cobertura em cor clara aumentar aumento da reflexão. \\
\hline
\end{tabular}

Tabela 3 - Energia e Atmosfera - Estratégias

Fonte: 0 s autores

Conforme indicação do LEED, foi prevista a permanência de paredes, pisos, coberturas e elementos não estruturais interiores existentes, e tais elementos foram mantidos, por vezes com novos revestimentos, como na fachada e terraços que apresentavam manifestações patológicas. Na Tabela 4 estão exemplificadas outras estratégias definidas para satisfazer os critérios previstos. de compostos orgânicos voláteis, como pisos vinílico certificados e tintas ecológicas. A Tabela 5 exemplifica outras estratégias adotadas para estes requisitos.

\section{d) Satisfação dos Usuários}

Tendo em vista que a empresa continuaria em pleno funcionamento e a permanência dos usuários no prédio, durante as intervenções, foram definidas estratégias que minimizassem os impactos no ambiente de trabalho, optando pela utilização de estrutura metálica e placa cimentícia para fechamentos externos, gesso acartonado e vidro temperado para divisórias internas, e o envelopamento da fachada em ACM, buscando acelerar a execução, evitar sujeira e desperdício de materiais. Tais sistemas construtivos tem como características a rapidez e a menor geração de resíduos.

\begin{tabular}{|c|c|c|}
\hline \multirow{6}{*}{\multicolumn{2}{|c|}{ 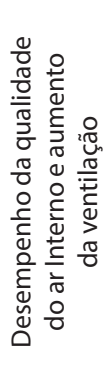 }} & $\begin{array}{l}\text { Instalar sistema de ventilação forçada, acionados por sensor de } \\
\text { presença, nos banheiros que não possuem ventilação natural. }\end{array}$ \\
\hline & & $\begin{array}{l}\text { Aumentar os vãos das janelas proporcionando mais venti- } \\
\text { lação natural. }\end{array}$ \\
\hline & & $\begin{array}{l}\text { Reformular o layout e reposicionar os funcionários para que } \\
\text { todas as áreas de trabalho tivessem ventilação natural. }\end{array}$ \\
\hline & & Retirar paredes não portantes para integração dos espaços. \\
\hline & & Fazer ligação entre os dois prédios no pavimento superior. \\
\hline & & Ambientar todas as áreas com vegetação natural. \\
\hline \multirow{8}{*}{ 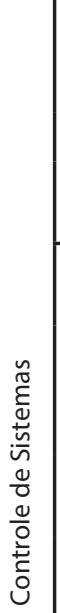 } & \multirow{3}{*}{ 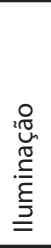 } & $\begin{array}{l}\text { Instalar tela solar externa em todas as janelas das áreas de } \\
\text { trabalho, para evitar reflexo nos monitores e reduzir a en- } \\
\text { trada do calor. }\end{array}$ \\
\hline & & Instalar película protetora nos vidros das janelas. \\
\hline & & $\begin{array}{l}\text { Redistribuir os circuitos elétricos para controle indepen- } \\
\text { dente da iluminação nas áreas de trabalho e circulações. }\end{array}$ \\
\hline & \multirow{5}{*}{ 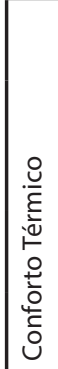 } & $\begin{array}{l}\text { Instalar dois tipos de brises, sendo um na fachada oeste e } \\
\text { outro na fachada norte, para bloquear a incidência solar. }\end{array}$ \\
\hline & & Utilizar paisagismo para bloquear o sol na fachada oeste. \\
\hline & & $\begin{array}{l}\text { Renovar a pintura e escolher revestimentos de fachada em } \\
\text { tons claros. }\end{array}$ \\
\hline & & $\begin{array}{l}\text { Pintar a cobertura de cor clara para aumentar a reflexão } \\
\text { dos raios solares. }\end{array}$ \\
\hline & & $\begin{array}{l}\text { Dimensionar o sistema de } \mathrm{AC} \text {, conforme as áreas, usos e } \\
\text { incidência de calor nos ambientes. }\end{array}$ \\
\hline
\end{tabular}




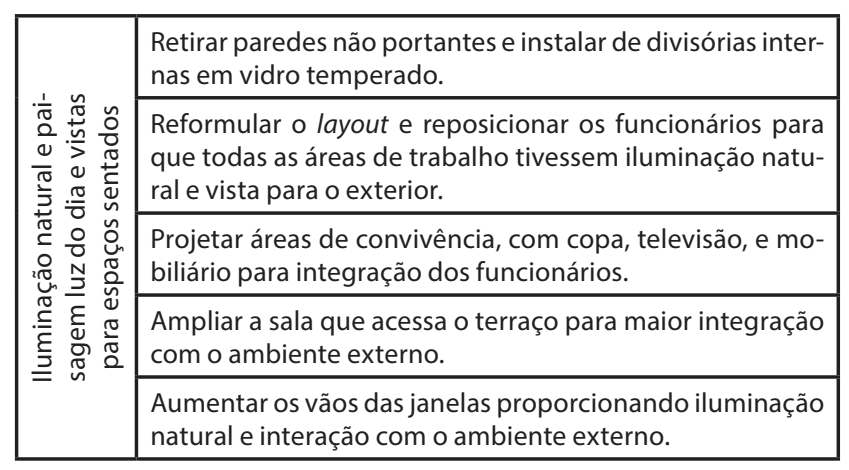

Tabela 5 - Qualidade Ambiental Interna - Estratégias Fonte: 0 s autores

Além disso, foram propostas diretrizes para aumentar a satisfação dos usuários, incluindo a utilização dos sanitários desativados, e um espaço de convivência amplo, iluminado e confortável, com banquetas, mesas baixas, sofás e televisores para o uso dos espaços tanto no horário das refeições quanto ao longo do dia, e onde fosse possível reunir toda a equipe em datas importantes.

Por se tratar de um retrofit, com ampliação de área, foram consultados o Plano Diretor, e o Código de Obra do município, para avaliar a taxa de ocupação, o índice de aproveitamento, recuos exigidos para o segundo pavimento e o dimensionamento dos vãos de iluminação e ventilação. Ainda, foram propostas melhoria para acessibilidade, conforme exigências da NBR 9050 (ABNT,2015), incluindo a execução de uma rampa para acessar o prédio, a instalação de um sanitário adaptado para portadores de necessidades especiais e a integração total do segundo pavimento.

\subsection{Desenvolvimento de Projetos}

O projeto arquitetônico foi desenvolvido a partir das diretrizes e informações obtidas anteriormente, e foram desenvolvidas 2 propostas para chegar no projeto definitivo. $O$ ponto de partida foi a revisão do layout, propondo o aumentar do número de sanitários e a integração dos espaços para acomodar todos os setores o mais próximo possível.

No térreo (Figura 11) foi proposta a ampliação do sanitário feminino, a construção de um novo sanitário masculino e de um sanitário acessível junto a uma ampla nova área de convivência, bem como, uma rampa no acesso secundário.

No segundo pavimento (Figura 12) foi proposta uma ampliação no sanitário feminino e a ocupação de uma parte do terraço para que toda a controladoria ficasse num mesmo ambiente. Estabeleceu-se também como seria realizada a ligação entre os prédios e a relocação do setor de compras para a área que ficava desocupada.

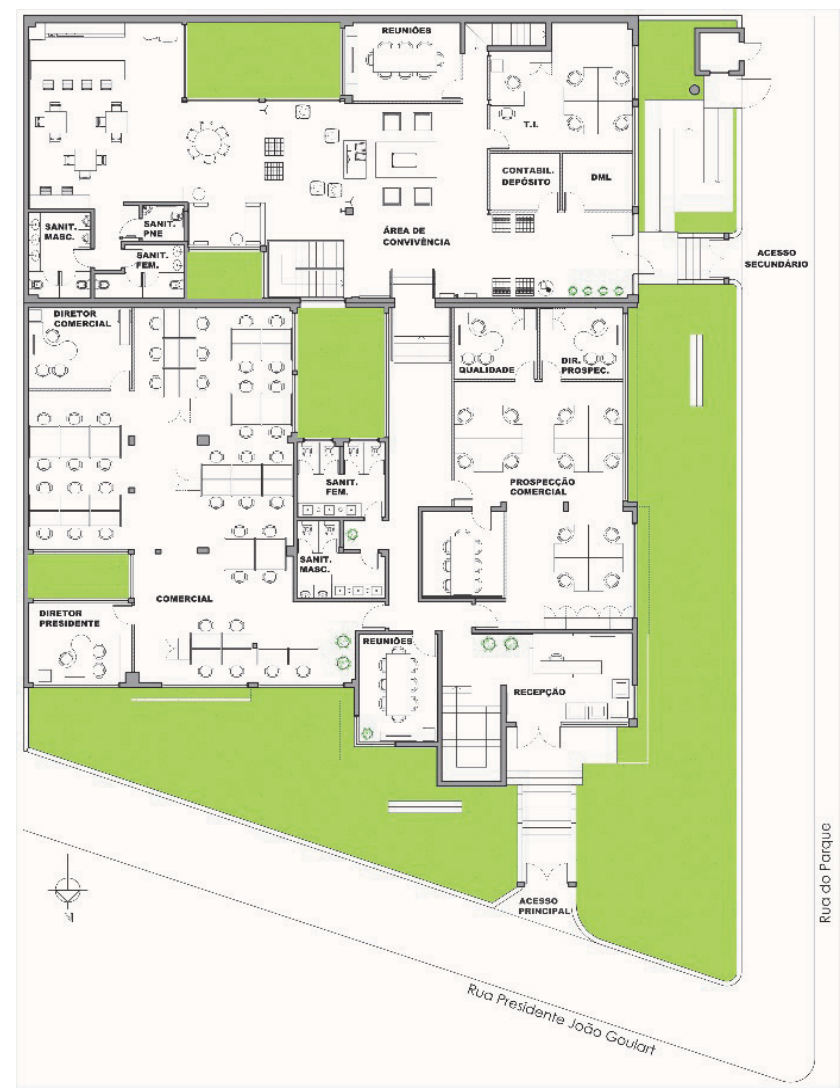

Figura 11 - Planta baixa - Novo layout térreo

Fonte: 0 s autores

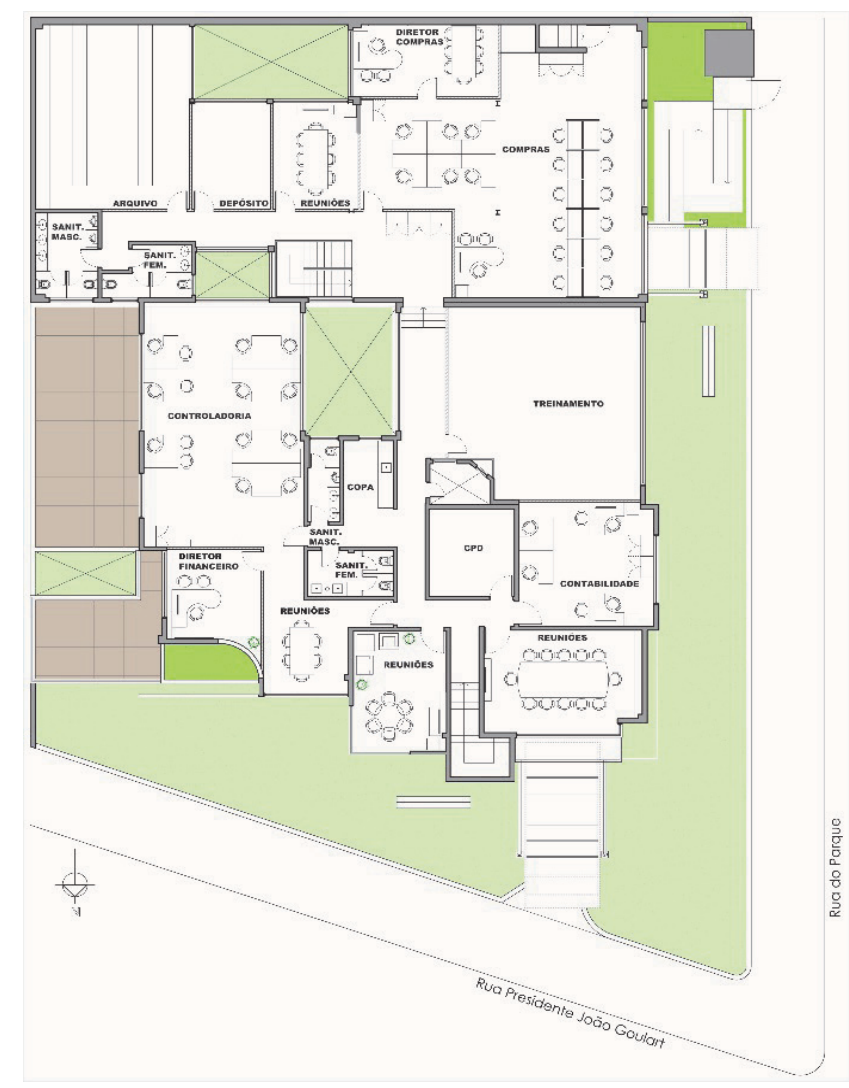

Figura 12 - Planta baixa - Novo layout 20 pavimento Fonte: 0 s autores 
Para resolver questões de iluminação e ventilação natural, bem como a relação das vistas internas e externas, foram propostos aumentos nos vãos das janelas com o peitoril alto, demolição de alvenarias para ampliar os ambientes e instalação de divisórias de vidro, com diferentes graus de translucides para não criar barreiras visuais. Na iluminação geral foi realizado cálculo luminotécnico e redistribuição dos circuitos elétricos. Para o conforto térmico, foram dimensionados aparelhos de ar condicionado, e realizada uma nova distribuição entre aparelhos novos e existentes, para que houvesse maior autonomia por parte dos usuários. Nesta etapa também foi definida a troca de todos os revestimentos de piso internos, por piso vinílico tipo cimento queimado, com exceção dos banheiros que receberam porcelanato no piso e pintura epóxi nas paredes.

Os estudos de fachada foram feitos em $3 d$, conforme mostram a Figura 13. A primeira opção apresentada foi aprovada, só sendo realizados teste para definir as cores dos brises, sendo que as cores laranja e cinza foram escoIhidas, por serem as cores da marca da empresa.

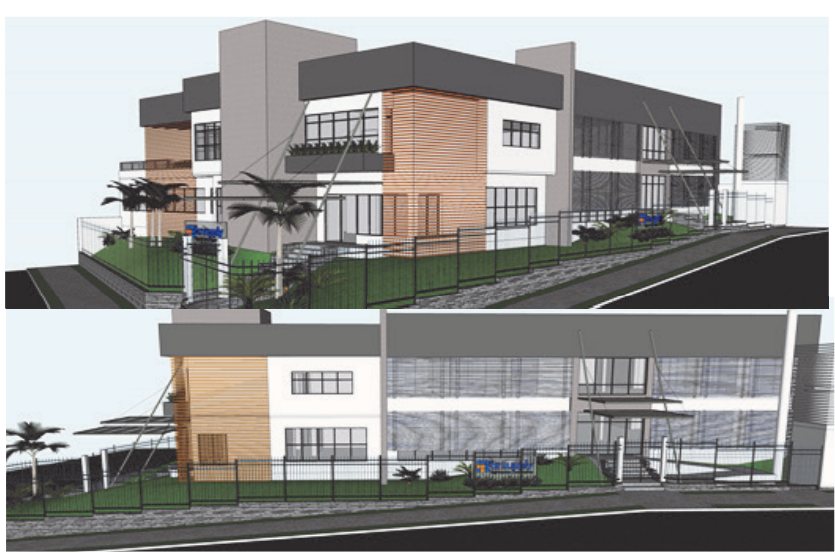

Figura 13 - Estudos de Fachada Fonte: 0 s autores

Durante o desenvolvimento do projeto optou-se pelo uso de brise-soleil, pois controlam a entrada de radiação solar nos ambientes, com a finalidade de proteger a edificação contra a incidência direta dos raios solares, redirecionando-os e redistribuindo-os pelo ambiente. $O$ dimensionamento e a escolha do modelo de brises foi feito através da análise da carta solar, que define o mascaramento - ângulo de sombreamento proporcionado pelo protetor solar, conforme a necessidade de desempenho térmico e luminoso da abertura. (LIMA; BITTENCOURT, 2012).

Utilizando programa gratuito de simulação, SOL-AR, desenvolvido pelo Laboratório de Eficiência Energética em Edificações (LabEEE) da Universidade Federal de Santa
Catarina (UFSC), com base em dados fornecidos pela empresa Refax, fabricante do brise metálico linear LC $10045^{\circ}$ (Figura 14), das informações de latitude e longitude, obtidas através do IBGE e informações da edificação, foi possível determinar a máscara de sombreamento para a fachada oeste.

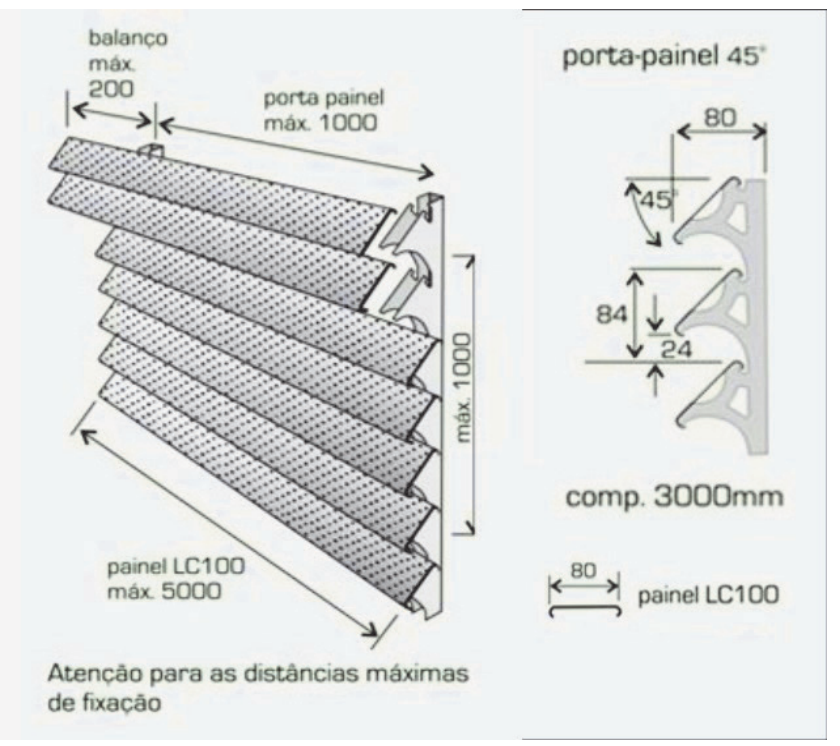

Figura 14 - Brises utilizados no estudo

Fonte: Empresa Refax (2014)

A eficiência foi analisada conforme os preenchimentos em vermelho da Figura 15, para horários em que há eficiência total, e amarelo, quando a eficiência é parcial.

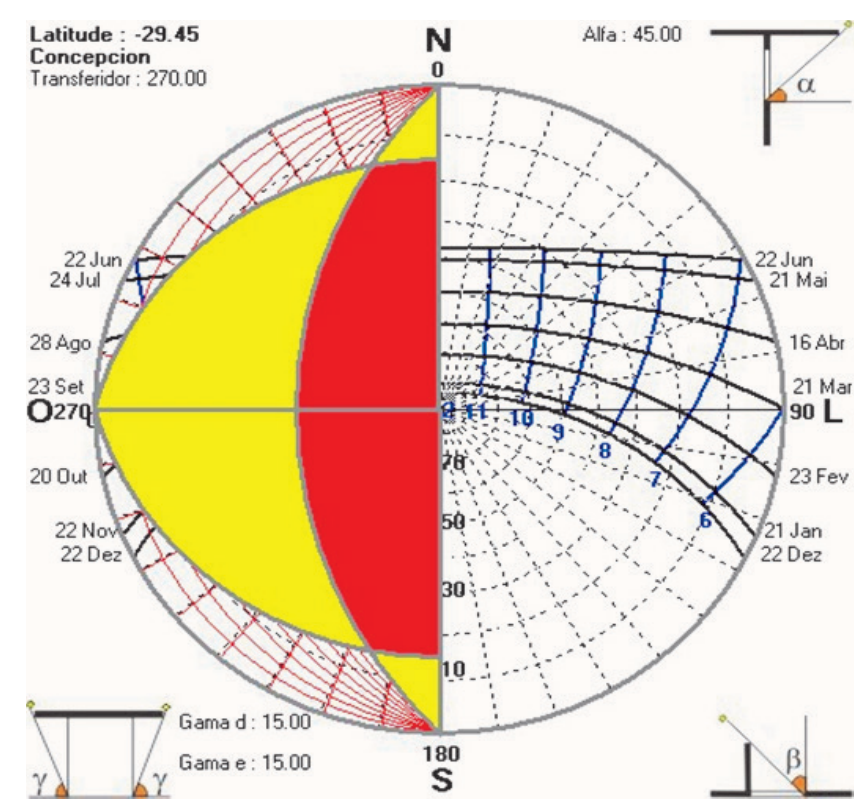

Figura 15 - Resultados do simulador SO-LAR

Fonte: 0 s autores

$\mathrm{Na}$ análise dos resultados, constatou-se que o sombreamento da fachada oeste, no período da tarde, ocorre 
de forma totalmente eficiente, a partir do meio dia, até as 15horas e 30 minutos, e após este horária até as 18 horas de forma parcial, conforme Figura 15.

\subsection{Acompanhamento da Execução do Retrofit}

Com o projeto arquitetônico definido foi elaborado um cronograma para que a empresa continuasse em funcionamento mesmo durante o período da obra. O retrofit teve duração de 8 meses e os funcionários foram deslocados de suas salas conforme necessário.

Através do acompanhamento da obra, um dos grandes problemas detectados foram as infiltrações, decorrentes de diversos motivos. Através da composição de imagens da Figura 16 pode-se perceber a evolução do tratamento para esta manifestação patológica na sala do departamento comercial.

No mesmo setor, foram realizadas outras intervenções, como a retirada do contrapiso para realizar impermeabilização, instalação de ar condicionado tipo cassete, execução de forro de gesso, substituição das lâmpadas por LED, redução dos peitoris das janelas, ampliando os vãos.
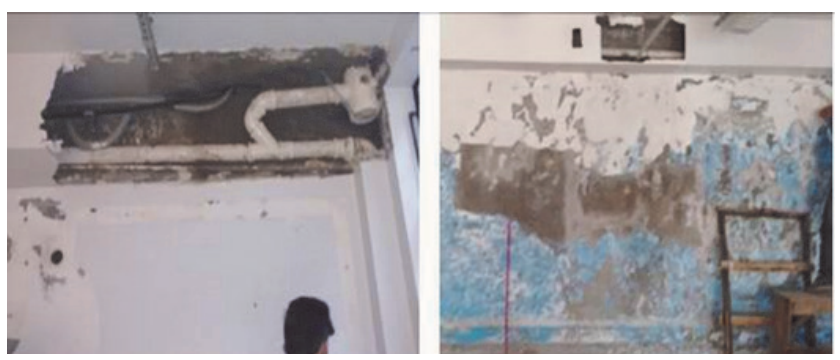

Figura 16 - Infiltrações

Fonte: 0 s autores

Na área de convivência, as paredes em alvenaria não portante foram demolidas para integração com a antiga direção comercial, bem como e a retirada do deck, a execução do contrapiso, a instalação das bandeiras de gesso acartonado para instalação dos perfis de alumínio e a fixação das divisórias de vidro temperado.

No espaço que era destinado ao depósito, havia problemas no forro de PVC e no sistema de cobertura, e foi realizada a substituição das telhas de fibrocimento, por telhas metálicas com isolamento térmico. O restante dos telhados recebeu pintura em cor clara para reduzir os efeitos de ganhos de calor, conforme indicado em estudos de Silva e Goulart (2012). Durante a execução foram realizadas manutenções nas esquadrias, substituição de vidros e instalação de películas, além da manutenção e limpeza dos filtros de ar condicionados reaproveitados. Além disso, a mesma telha térmica foi utilizada sobre a estrutura metálica da área construída para receber o departamento financeiro. O fechamento desta área foi executado em placa cimentícia e esquadrias de vidro temperado (Figura 17).
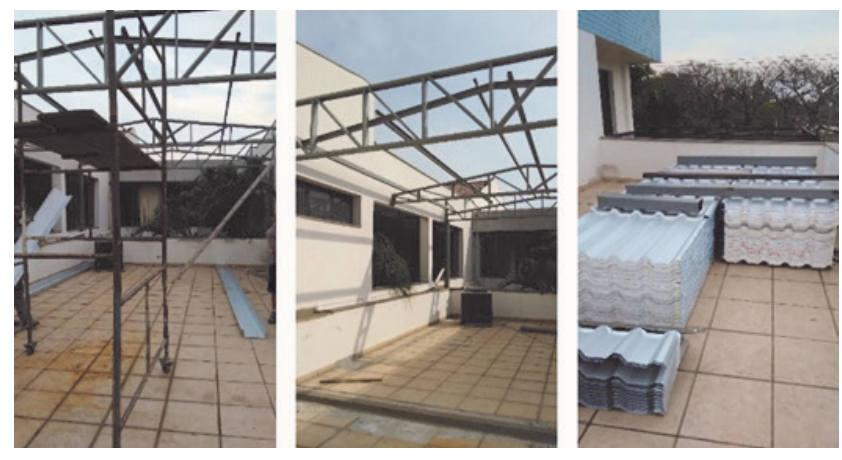

Figura 17 - Nova estrutura metálica do Departamento Financeiro Fonte: 0 s autores

Uma das maiores necessidades da empresa era criar uma fachada que comunicasse sua busca constante por inovação e seu posicionamento sustentável. A evolução das modificações na esquina da edificação pode ser observada na Figura 18, em que aparece a retirada das pastilhas cerâmicas, a instalação do porcelanato no volume da escada, o envelopamento das platibandas em ACM, e a instalação dos brises na cor laranja.

A fachada lateral, de acesso secundário, recebeu uma rampa e um novo portão, além da construção de um painel em alvenaria revestido com porcelanato, tipo concreto aparente, para demarcar a área onde foram instalados os brises calculados para fachada oeste. Ao término da obra foram instaladas telas solares nas janelas e vegetação natural para decoração e purificação do ar em todos os ambientes.
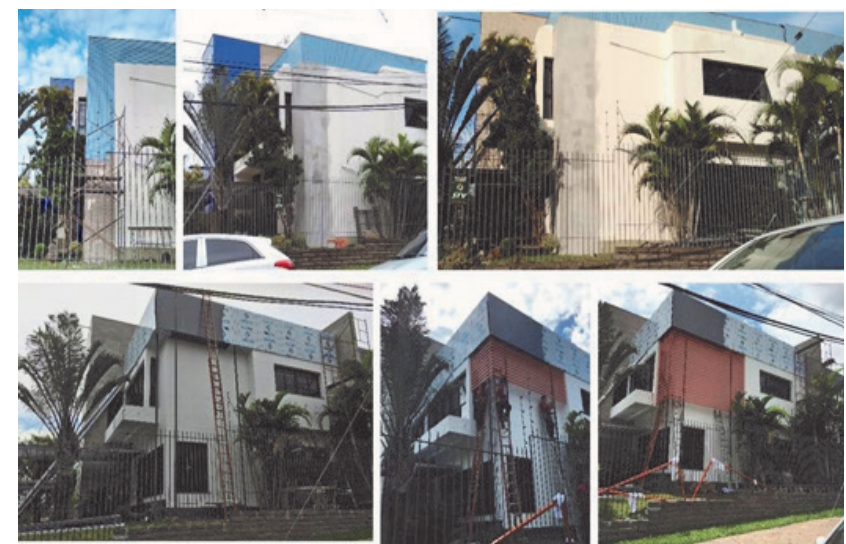

Figura 18 - Fachada durante a reforma Fonte: 0 s autores 


\subsection{Comparativo dos Questionários}

As obras foram finalizadas em maio de 2016, quando foi aplicado aos usuários um novo questionário de APO idêntico ao primeiro, e as respostas foram comparadas com as anteriores gerando os gráficos apresentados a seguir, possibilitando mensurar se as estratégias adotadas tiveram impacto na qualidade do ambiente e na satisfação dos usuários, antes e depois do retrofit.

O comparativo foi estabelecido em forma de percentual pois o primeiro questionário foi respondido por 41 usuários, enquanto o segundo questionário foi respondido por todos os 61 usuários que trabalham no prédio. Mesmo com pequenas variações entre as respostas, em ambos os resultados a maioria dos usuários são do gênero feminino, com idades entre 20 e 40 anos, e passam entre 8 e 10 horas no ambiente de trabalho.

A Figura 19 mostra a porcentagem de usuários satisfeitos com cada item avaliado antes e depois da execução do retrofit.

$\mathrm{Na}$ questão sobre a acessibilidade do prédio, o índice de satisfação já era alto, de $92,68 \%$, e mesmo com as meIhorias de ligação no segundo pavimento, execução de rampa de acesso e sanitário adaptado para PNE, no segundo questionário este resultado diminui um pouco para $90,32 \%$, porém este fato pode estar ligado ao fato de que com a reformulação do layout mais funcionários passaram a trabalhar no segundo pavimento, necessitando utilizar as escadas com mais frequência. Além disso, as pessoas que não haviam respondido ao primeiro questionário podem ter contribuído com uma percepção negativa desse fator.

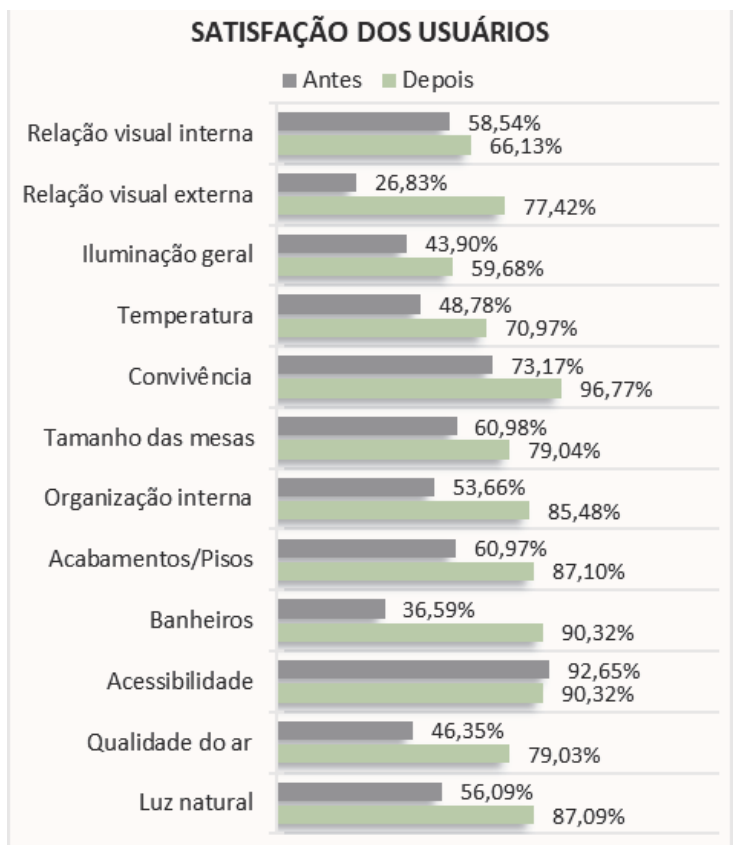

Figura 19 - Comparativo dos Questionários Fonte: 0 s autores
Para mais, a interferência dos ruídos internos e externos era insatisfatória para $56,1 \%$ e $21,95 \%$ dos usuários, respectivamente. Ao término da obra estes valores passaram para $17,75 \%$ e $4,84 \%$, indicando que o posicionamento correto das estações de trabalho na distribuição do layout causa menos interferência de ruídos entre os usuários, e que o fato de ter mais aberturas para a rua não necessariamente causa o aumento de ruídos internos.

Mesmo que as áreas de convivência antigas satisfizessem $73,17 \%$ dos usuários, estas foram melhoradas e a pesquisa revelou que $66,85 \%$ dos usuários utilizavam pouco estes espaços. Com um aumento da satisfação para $96,77 \%$, as taxas de ocupação aumentaram, mas de maneira pouco significativa, pois ainda assim $51,61 \%$ utilizam pouco estas áreas. $O$ proprietário da empresa, também entrevistado, indicou que tal fato pode estar relacionado com a alta rotatividade de funcionários, pois a maioria dos usuários destes espaços ainda não se sentem à vontade em fazer reuniões informais com colegas e realizar uma pausa fora da estação de trabalho. Cabe destacar que a rotatividade não impactou na aplicação dos questionários, sendo que, dos 41 funcionários que responderam ao primeiro questionário, 38 ainda estavam na empresa na aplicação do segundo.

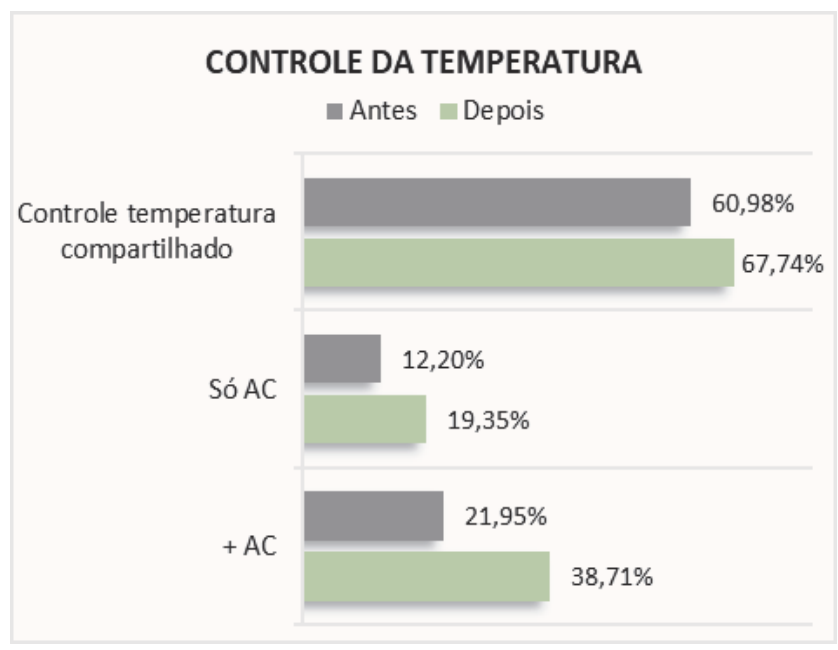

Figura 20 - Comparativo dos questionários - Controle da Temperatura Fonte: 0 s autores

Conforme as avaliações em relação à temperatura e uso de ar condicionado percebe-se que houve um aumento no consumo de ar condicionado (Figura 20), porém o controle da temperatura e do tipo de ventilação do ambiente passou a ser mais compartilhado. Lamberts, Dutra e Pereira (2014) relatam que em ambientes onde o usuário possui maior controle sobre a temperatura os índices de satisfação são maiores. Em relação à preferência dos usuários, quanto 
a iluminação, foi possível avaliar que houve uma redução na utilização de iluminação artificial (Figura 21), pois mesmo que tenha sido realizada uma redistribuição e acréscimo de luminárias, por outro lado a ampliação nos vãos das janelas trouxe mais luz para o prédio. As médias de controle da iluminação também foram alteradas, uma vez que aumentou o número de usuários com controle compartilhado.

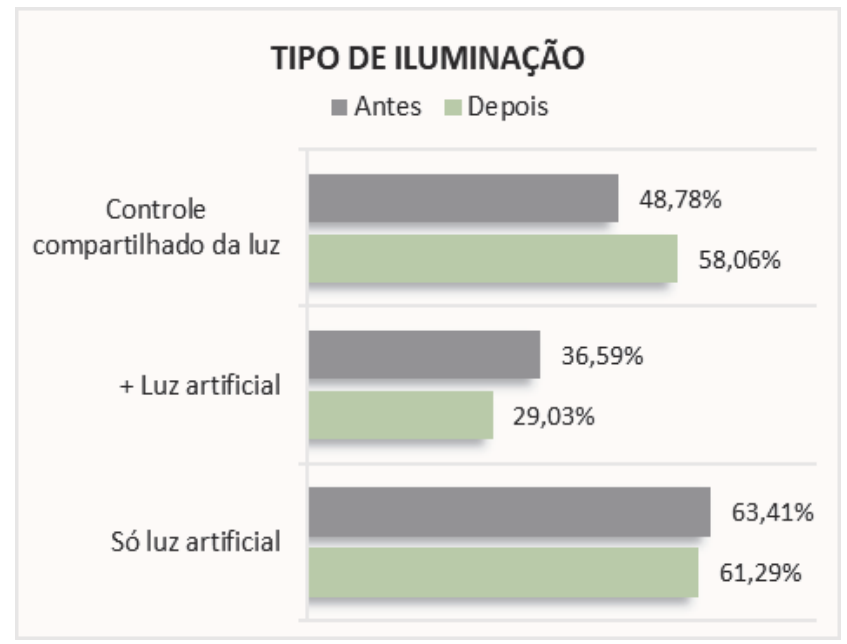

Figura 21 - Comparativo dos questionários - Tipos de lluminação Fonte: 0 s autores

A última pergunta dos dois questionários era sobre a opinião dos usuários referente à importância do consumo consciente de água e energia elétrica em uma empresa, e foi incluído como solicitação da empresa para definir qual seria a melhor abordagem para as campanhas de conscientização e práticas sustentáveis que ela pretende aplicar. Como resultado, houve uma redução daqueles que acreditam que sejam práticas para preservação do meio ambiente - de 70,73\% para 62,90\% - e aumento daqueles que acreditam ser medidas para redução de custos - de $19,51 \%$ para $30,65 \%$. Para aqueles que acreditam ser para promoção de um marketing de sustentabilidade, houve uma redução de $9,76 \%$ para $6,45 \%$.

\section{CONCLUSÕES}

Muitas vezes, ao contratar o serviço de um arquiteto, o cliente deseja realizar reformas priorizando a redução dos custos e tempo de obra. Especialmente quando se trata de retrofit corporativo, não se pode haver interrupções para as intervenções que possuam prazos curtos para ocorrer, o que inviabiliza a tomada de algumas decisões, tanto na fase de projeto quanto na obra, que poderiam melhorar a qualidade do ambiente construído. Um projeto desenvolvido e elaborado para atender as demandas especíicas da empresa, possibilita adequar a edificação às evoluções da tecnologia, internet, cabeamento, iluminação, além de permitir que sejam aplicados conceitos de sustentabilidade, como eficiência hídrica e energética, que promovem a redução de consumo dos recursos naturais e economia à longo prazo.

O estudo de caso, desenvolvido a partir da realização de um retrofit na sede da empresa BR Supply, foi pautado pela adoção de diretrizes projetuais de sustentabilidade, estabelecidos pela Certificação LEED para grandes reformas e interiores comerciais, com o intuito de melhorar a qualidade do ambiente e avaliar a satisfação dos usuários mediante as estratégias adotadas. $\mathrm{O}$ ponto de partida para o desenvolvimento do projeto, foi a revisão do layout para acomodar todos os setores de maneira próxima promovendo a integração dos espaços.

Ambientes confortáveis, agradáveis e adequados demostram preocupação com os usuários e geram comprometimento, credibilidade e confiança. Quando uma empresa necessita se posicionar e passa por mudanças internas é importante também alterar a fachada, o que possibilita transmitir aos clientes, fornecedores e funcionários os interesses e valores da empresa, não só através de seus espaços internos e como também externos. Para tanto, na edificação em questão foi elaborado um projeto de fachada, contemplando elementos que solucionassem os problemas de insolação, como brises e vegetação.

Em uma análise geral, foi possível perceber que na grande maioria dos resultados de satisfação, medidos através de questionários antes e após a execução do retrofit, houve um aumento no percentual de satisfação dos usuários, tanto nos aspectos relacionados ao conforto, como iluminação, ventilação, interferência de ruídos internos e externos, quanto nos relacionados a organização e acabamentos do ambiente. Vale ressaltar que a rotatividade da empresa analisada não permite uma avaliação fidedigna dos resultados, porque, no início e no final da obra, não foram as mesmas pessoas que responderam aos questionários.

Com este trabalho foi possível perceber que com a aplicação de estratégias sustentáveis em um retrofit, é possível qualificar o ambiente interno para oferecer bem-estar aos usuários, gerando economia, aliando estética e funcionalidade. A função do arquiteto é projetar de maneira a criar espaços convidativos e aconchegantes, mas a postura e a política interna da empresa devem estar claras e alinhadas para que os usuários possam fazer uso destes locais, pois como se observou no decorrer da pesquisa, alguns usuários evitam as áreas de convivência por se sentirem intimidados ou desconfortáveis em sair de seus locais de trabaIho para tomar um café, por exemplo. No caso da empresa analisada, tal prática é permitida, mas não incentivada. 


\section{REFERÊNCIAS}

AGOPYAN, V.; JOHN, V. M. O Desafio da Sustentabilidade na Construção Civil. São Paulo: Blucher, 2012. $144 \mathrm{p}$. ASSOCIAÇÃO BRASILEIRA DE NORMAS TÉCNICAS. NBR 9050: Acessibilidade a edificações, mobiliário, espaços e equipamentos urbanos. Rio de Janeiro, 2015.

FONSECA, Juliana Figueiredo. A contribuição da ergonomia ambiental na composição cromática dos ambientes construídos de locais de trabalho de escritório. 2004. 292f. Dissertação (Mestrado em Design) - Programa de Pós-Graduação em Design, Pontífera Universidade Católica do Rio de Janeiro (PUC-Rio), Rio de Janeiro, 2004.

GURGEL, Miriam. Projetando Espaços: Guia de arquitetura de interiores para áreas comerciais. 5. ed. São Paulo: Senac. 2014.

ISSA, Maíra P.; POLTRONIERI, Julyane P.; ORNSTEIN, Sheila W. Procedimentos para Avaliação Pós-Ocupação (APO) de Edifícios Escolares: O Caso da E.E. Fernando Gasparian, na cidade de São Paulo. In: NUTAU 2008. Anais eletrônicos... São Paulo: USP, 2008.

LAMBERTS, Roberto; DUTRA, Luciano; PEREIRA, Fernando O. R. Eficiência Energética na Arquitetura. São Paulo: Eletrobrás, 2014. 366 p.

LIMA, Kamila Mendonça de; BITTENCOURT Leonardo Salazar. Efeito do espaçamento, inclinação e refletância de brises horizontais com mesma máscara de sombra na lluminação natural e ganhos térmicos em Escritórios em Maceió - AL. In: ENCONTRO NACIONAL DE TECNOLOGIA DO AMBIENTE CONSTRUÍDO ENTAC, XIV, 2012, Juiz de Fora. Anais eletrônicos... Juiz de Fora: Centro de Referência e Informação em Habitação, 2012. Disponível em: http://www.infohab. org.br/entac2014/2012/docs/1486.pdf

MORAES, Virginia Tambasco Freire; QUELHAS Osvaldo Luiz Gonçalvez. Programa de Engenharia de Produção, UFF. pg 448-461. 0 desenvolvimento da metodologia e os processos de um retrofit arquitetônico. Revista Eletrônica Sistema \& Gestão, Volume 7, número 3. Niterói, 2012.

ONO, R.; ORNSTEIN, S. W.; VILLA, S. B.; FRANÇA, A. J. G; L. Avaliação Pós-Ocupação na Arquitetura, no Urbanismo e no design: da teoria à prática. 1. ed. São Paulo: Oficina de Textos, 2018.

PIQUETTI, Tammi. Uso da arquitetura para qualidade de vida nas empresas. Especialize revista on-line IPOG, Florianópolis, v.4, 2012. Disponível em: $\quad$ http://www.ipog.edu.br/uploads/arquivos/ eddbc6d6b354a289ac7b699622ffd62a.pdf . Acesso em 10 jul. 2015.

PNUMA - Programa das Nações Unidas para o Meio Ambiente. Aspectos da Construção Sustentável no Brasil e Promoção de Políticas Públicas: subsídios para a promoção da construção civil sustentável. São Paulo: Conselho Brasileiro de Construção Sustentável, 2014. 133 p.

RHEINGANTZ, Paulo Afonso et al. Observando a qualidade do lugar: procedimentos para a avaliação pós-ocupação. Rio de Janeiro: Coleção PROARQ, Faculdade de Arquitetura da Universidade Federal do Rio de Janeiro (FAU-UFRJ), 2009.

SILVA, M. M. G.; GOULART, Solange. Princípios de sustentabilidade aplicados ao processo de projeto de edificações: uma ferramenta de auxílio ao projeto. In: ENCONTRO NACIONAL DE TECNOLOGIA DO AMBIENTE CONSTRUÍDO - ENTAC, XIV, 2012, Juiz de Fora. Anais eletrônicos...Juiz de Fora: Centro de Referência e Informação em Habitação, 2012.

SILVA, V. G.; PARDINI, A. F. Aplicação da certificação LEEDTM no Brasil: contribuição ao entendimento com base em dois estudos de casos. PARC Pesquisa em Arquitetura e Construção, Campinas, v. 1, n. 6, p. 115-130, 2011.

VALE, Mauricio Soares do. Diretrizes para a racionalização e atualização das edificações: segundo o conceito da qualidade e sobre a ótica do retrofit. 2006. 220f. Dissertação (Mestrado em Ciências em Arquitetura) - Programa de Pós-Graduação em Arquitetura, Universidade Federal do Rio de Janeiro (UFRJ), Rio de Janeiro, 2006.

\section{AGRADECIMENTOS}

Agradecemos à BR Supply pelo suporte dado ao estudo e pela autorização na divulgação das informações. 


\section{AUTORES}

ORCID: https://orcid.org/0000-0003-4853-3423

ISABELA FRANCO SCHREIBER, M.Sc. | Unisinos | PPG Arquitetura e Urbanismo | São Leopoldo, RS - Brasil | Correspondência para: Av. Unisinos, 950 - Bairro Cristo Rei, São Leopoldo/ RS, 93.022-750 | E-maill: isabela@duo-arquitetura.com

ORCID: https://orcid.org/0000-0003-1440-0315

MATHEUS VANZIN VERONA | Unisinos | ITT Performance | São Leopoldo, RS - Brasil | Correspondência para: Av. Unisinos, 950 - Bairro Cristo Rei, São Leopoldo/RS, 93.022-750

E-maill: matheusverona@live.com

ORCID: https://orcid.org/0000-0003-3455-491X

FERNANDA PACHECO, M.Sc. | Unisinos | itt Performance | São Leopoldo, RS - Brasil | Correspondência para: Av. Unisinos, 950 - Bairro Cristo Rei, São Leopoldo/RS, 93.022-750 | E-maill: fernandapache@unisinos.br

ORCID: https://orcid.org/0000-0002-6097-5008

DANIEL REIS MEDEIROS, Dr. | Unisinos | PPG Arquitetura e Urbanismo e itt Performance | São Leopoldo, RS - Brasil | Correspondência para: Av. Unisinos, 950 - Bairro Cristo Rei, São Leopoldo/RS, 93.022-750 | E-maill: drmedeiros@ unisinos.br

ORCID: https://orcid.org/0000-0001-5369-688X

MARIA FERNANDA DE OLIVEIRA, Dra. | Unisinos | PPG Arquitetura e Urbanismo e itt Performance | São Leopoldo, RS - Brasil | Correspondência para: Av. Unisinos, 950 - Bairro Cristo Rei, São Leopoldo/RS, 93.022-750 | E-maill: mariaon@unisinos. br

\section{COMO CITAR ESTE ARTIGO}

SCHREIBER, Isabela Franco; VERONA, Matheus Vanzini; PACHECO, Fernanda; MEDEIROS, Daniel Reis; OLIVEIRA, Maria Fernanda. Sustentabilidade, Certificação LEED e Usuário: Estudo em Retrofit de Edifício Corporativo. MIX Sustentável, [S.I.], v. 6, n. 3, p. 91-106, jun. 2020. ISSN 24473073. Disponível em:<http://www. nexos.ufsc.br/index.php/mixsustentavel $>$. Acesso em: dia mês. ano. doi:https://doi.org/10.29183/2447-3073. MIX2020.v6.n3.91-106.

DATA DE ENVIO: 20/10/2019

DATA DE ACEITE: 20/05/2020 
